\title{
Drivers and Determinants of Food Waste Generation in Restaurants Serving Mediterranean Mezze-Type Cuisine
}

\author{
Ali Chalak ${ }^{1,+}$ (D) , Hussein F. Hassan ${ }^{2,+}$, Pamela Aoun ${ }^{3}(\mathbb{D})$ and Mohamad G. Abiad ${ }^{3,4, *(D)}$ \\ 1 Department of Agriculture, Faculty of Agricultural and Food Sciences, American University of Beirut, \\ P.O. Box 11-0236, Riad El Solh, Beirut 1107-2020, Lebanon; ac22@aub.edu.lb \\ 2 Nutrition Program, Department of Natural Sciences, School of Arts and Sciences, \\ Lebanese American University, P.O. Box 13-5053, Chouran, Beirut 1102-2801, Lebanon; \\ hussein.hassan@lau.edu.lb \\ 3 Department of Nutrition and Food Sciences, Faculty of Agricultural and Food Sciences, \\ American University of Beirut, P.O. Box 11-0236, Riad El Solh, Beirut 1107-2020, Lebanon; \\ pga09@mail.aub.edu \\ 4 Laboratories for the Environment, Agriculture, and Food (LEAF), Faculty of Agricultural and Food Sciences, \\ American University of Beirut, P.O. Box 11-0236, Riad El Solh, Beirut 1107-2020, Lebanon \\ * Correspondence: ma192@aub.edu.lb; Tel.: +961-1-350000 (ext. 4412) \\ + These authors have contributed equally to this manuscript.
}

Citation: Chalak, A.; Hassan, H.F.; Aoun, P.; Abiad, M.G. Drivers and Determinants of Food Waste Generation in Restaurants Serving Mediterranean Mezze-Type Cuisine. Sustainability 2021, 13, 6358. https:// doi.org/10.3390/su13116358

Academic Editors: Gaetano Chinnici and Giuseppe Antonio Di Vita

Received: 21 April 2021

Accepted: 18 May 2021

Published: 3 June 2021

Publisher's Note: MDPI stays neutral with regard to jurisdictional claims in published maps and institutional affiliations.

Copyright: (c) 2021 by the authors. Licensee MDPI, Basel, Switzerland. This article is an open access article distributed under the terms and conditions of the Creative Commons Attribution (CC BY) license (https:/ / creativecommons.org/licenses/by/ $4.0 /)$.

\begin{abstract}
Food waste from the food service and hospitality industry is increasing, especially in Mezze serving restaurants, where a variety of dishes are usually served. To date, information on the factors affecting food waste generation in restaurants is scarce. This study aimed to identify the drivers and determinants of food waste generation while dining out at restaurants serving Mezze-type cuisine. According to the results from a convenience sample of 496 restaurant clientele, gender, age, and marital status did not affect food waste generation. Diners in both low and high price range restaurants waste above the grand mean compared to middle-range ones. Waste generation decreased significantly as the number of diners per table increased. However, ordering water-pipe, alcohol, or more dishes contributed significantly to food waste generation. As food waste is not the outcome of a single behavior, our study puts food waste generation drivers and determinants while dining out in perspective.
\end{abstract}

Keywords: food waste; post-consumer waste; restaurants; dining out; waste

\section{Introduction}

The projections of a world population increase to 9.6 billion individuals by 2050 has driven many commentators to note that food production needs to increase by a minimum of $70 \%$ to keep up with the pace [1-3]. However, increasing food production requires extensive use of resources, such as land, water, and fuel, among others, all of which are associated with massive environmental and economic burdens on the very populations they aim to feed adequately. Additionally, food producers are often challenged with massive competition for these resources, thus limiting the quantity of food that can be produced. A promising solution in this regard is to reduce the amount of food lost and wasted [4-8].

The Food and Agriculture Organization (FAO) describes "food loss" as a decrease in edible food in quantity or quality, typically occurring during production and distribution along the food supply chain, mainly due to the production and food supply system's performance or its institutional and legal frameworks. On the other hand, "food waste" is considered to be suitable food for human consumption that has been disregarded from the food supply chain by choice or because it has spoiled or expired. Food waste can be attributed to economic or social behavior, poor stock management, or neglect at the retail, hospitality, or consumer levels [9]. Reducing food waste, including that generated 
by restaurants, can save what is equivalent to $30 \%$ of available land used in agriculture, reduce greenhouse emissions, and feed malnourished people [10].

Much research has been carried out on household food waste but not the waste generated in the hospitality sector [11]. Food waste from the food service and hospitality industry is rising, especially since food is increasingly consumed out-of-home [12]. This can be attributed to increasing work hours, rapid urbanization, dietary transition, and lifestyle changes [13]. Additionally, consumers are spending more money on dining out than on groceries, which may be attributed to long working hours or a lack of cooking skills [14]. It is estimated that food services generate 20 to $25 \%$ of food waste, with plate waste being the largest waste source [15]. Plate waste is defined as the quantity of edible parts of the food served that has not been eaten [13]. According to the Food and Brand Lab at Cornell University, diners leave on average $17 \%$ of their meals uneaten, with $55 \%$ of edible leftovers being left at the restaurant [16]. A study conducted in the UK showed that more than a quarter of the respondents left food at the end of their meal [17]. To effectively control food waste in restaurants, it should become a component of the restaurants' management system [18]. Most of the studies in the literature on food waste at restaurants focus mainly on the quantity, rather than on the underlying causes, and the information on this issue remains scarce for Arab countries, including Lebanon [19,20].

Mezze is an essential component of Lebanese cuisine, not least in restaurants. It is similar to Tapas of Spain, Mezeluri of Romania, and Stuzzichini of Italy. Mezze consists of an elaborate variety of hot and cold small dishes placed before guests, creating a wide selection of flavors, colors, aromas, and textures. It may be as simple as bread, raw vegetables, pickles, and dips, such as hummus and baba ghannouj, or it may be a complete meal that consists of salads, grilled meats, and desserts. Mezze dishes are generally shared by different people at the table and consumed in small bites using a piece of flatbread. It can range from twenty to sixty dishes, making food waste inevitable [21,22].

In Lebanon, $60 \%$ of the people face challenges in getting enough to eat. Furthermore, it is estimated that $52.5 \%$ of the municipal solid waste in Lebanon is organic, mainly food debris and waste [23]. Such inefficiencies need immediate attention and action, including efforts to reduce food waste, all the more so in light of the severe economic crisis ravaging the country since the summer of 2019 and its repercussions on poverty levels and food security. To effectively reduce food waste, a clear understanding of the drivers and determinants influencing consumers' behaviors and perceptions regarding food waste is required. Understanding quantities, reasons, and food waste patterns is essential for exploring strategies to reduce food waste at the restaurant level [24-26] assessed the determinants of food waste generation at the household level in Lebanon. [27] explored food waste generation in the hospitality and food retail and wholesale sectors in 44 countries with developed economies. To the best of the authors' knowledge, this study was the first of its kind that aimed to identify the drivers and determinants of food waste generation while dining out at restaurants serving mezze type/MediterraneanLebanese foods.

\section{Methodology}

\subsection{Questionnaire}

A questionnaire, composed of 33 questions, was developed in English and translated into Arabic to assess the drivers and determinants of food waste generation among consumers dining out at restaurants serving mezze/Lebanese food. The questionnaire was piloted on 50 participants. On average, each survey took up to $20 \mathrm{~min}$ to be completed. The questionnaire comprised three different sections. The first section covered the participants' demographic characteristics; the second section included attitudes and culturally relevant behaviors related to food waste; the third section included ethical and religious questions related to food waste. The study was approved for ethical compliance by the Institutional Review Board (IRB) at our institution. Informed consent was obtained from all subjects involved in the study. To ensure respondents' anonymity, no personal identifiers were 
collected. Participants were informed that the study was completely voluntary and that they could withdraw from the study at any time or refrain from answering any question.

\subsection{Study Population}

A convenience sample of 496 consumers dining out at different Lebanese restaurants located in the Greater Beirut area was interviewed between December 2018 and April 2019 by trained interviewers. The interview process consisted of two steps. First, the interviewer took the consent of the restaurant's manager to approach consumers while dining out. Next, the interviewer approached the consumers and explained the purpose of the study, its procedure, confidentiality, and risks/benefits to the participant. Each participant signed a written consent form to participate in the study. The study included only respondents over 18 and under 60 years of age. A full list of restaurants serving mezze/Lebanese food was obtained by using the Zomato application [28], which compiles all restaurants operating in Beirut, Lebanon. Zomato classifies restaurants into four categories based on the average meal price for two people. To ensure diversity among the restaurants, participants were recruited proportionally to the number of restaurants in each category. Sample characteristics are presented in Table 1.

Table 1. Socio-demographic characteristics of the study sample.

\begin{tabular}{lc}
\hline \multicolumn{1}{c}{ Participants' Characteristics } & $n=496$ \\
\hline Gender & $297(59.87)$ \\
Female & $199(40.12)$ \\
Male & \\
Age Group & $131(26.73)$ \\
18-24 & $178(36.33)$ \\
$25-34$ & $82(16.73)$ \\
35-44 & $68(13.88)$ \\
$45-54$ & $31(6.33)$ \\
55+ & \\
Marital Status & $269(54.23)$ \\
Single & $209(42.14)$ \\
Married & $13(2.62)$ \\
Divorced & $2(0.4)$ \\
Widowed & $3(0.96)$ \\
Refuse to answer & \\
Employment Status & $99(19.96)$ \\
Self-employed & $78(15.73)$ \\
Student & $254(51.21)$ \\
Employed & $65(13.10)$ \\
Unemployed & \\
Monthly Income & $21(4.23)$ \\
Less than USD 450 & $27(5.44)$ \\
Between USD 451 and USD 800 & $101(20.36)$ \\
Between USD 801 and USD 1600 & $75(15.12)$ \\
Between USD 1601 and USD 2399 & $60(12.1)$ \\
Between USD 2400 and USD 4499 & $51(10.28)$ \\
More than USD 4500 & $1612(32.46)$ \\
I don't know / Refuse to answer &
\end{tabular}

\subsection{Food Waste Collection and Measurement}

After completing the questionnaire, the interviewer waited for the consumers to finish eating, and then the waiter collected the remaining food in a plastic bag. The leftovers were then measured in grams using a portable balance. Knowing that Lebanese restaurants serve mezze-type foods, the dishes are always shared. For each survey, an average waste quantity was calculated by dividing the amount of food waste generated by the number of persons at the table. 


\subsection{Statistical Analysis}

Given the substantial amount of left-censoring at zero in the data, food waste was null for 156 respondents (i.e., 31.5\%). Model estimation was performed in a Tobit framework. Tobit models are recommended for fitting models with 'limited dependent' censored variables and are often referred to as 'corner-solution' models [29,30]. A set of covariates was selected to explain the systematic variation in food waste (expressed in grams per person). These are listed in Table 2, along with the proportions of their respective levels in the sample.

Table 2. List of covariate and sample characteristics.

\begin{tabular}{|c|c|c|c|c|c|}
\hline $\begin{array}{ll}\text { Variable } \\
\end{array}$ & $\mathbf{N}$ & Mean & Std. Dev. & Min. & Max. \\
\hline \multicolumn{6}{|l|}{ Restaurant's price range } \\
\hline LBP50,000 or less for 2 people & 146 & 0.294 & 0.456 & 0 & 1 \\
\hline LBP50,001-LBP120,000 for 2 people & 273 & 0.550 & 0.498 & 0 & 1 \\
\hline More than LBP120,000 for 2 people & 77 & 0.155 & 0.363 & 0 & 1 \\
\hline \multicolumn{6}{|l|}{ Number of people at the table } \\
\hline $1-2$ people & 250 & 0.504 & 0.500 & 0 & 1 \\
\hline 3-4 people & 168 & 0.339 & 0.474 & 0 & 1 \\
\hline 6 people or more & 78 & 0.157 & 0.364 & 0 & 1 \\
\hline \multicolumn{6}{|l|}{ Number of dishes per person } \\
\hline Up to 2 dishes & 254 & 0.512 & 0.500 & 0 & 1 \\
\hline $2-4$ dishes & 130 & 0.262 & 0.440 & 0 & 1 \\
\hline More than 4 dishes & 112 & 0.226 & 0.419 & 0 & 1 \\
\hline \multicolumn{6}{|l|}{ With whom are you dining out? } \\
\hline Alone/Friends/Colleagues & 253 & 0.510 & 0.500 & 0 & 1 \\
\hline Partner/Family & 243 & 0.490 & 0.500 & 0 & 1 \\
\hline \multicolumn{6}{|l|}{ Main motive for dining out } \\
\hline Leisure & 446 & 0.899 & 0.301 & 0 & 1 \\
\hline Business/Convenience & 50 & 0.101 & 0.301 & 0 & 1 \\
\hline \multicolumn{6}{|l|}{ Have you ordered narghile? } \\
\hline Yes & 250 & 0.504 & 0.500 & 0 & 1 \\
\hline No & 246 & 0.496 & 0.500 & 0 & 1 \\
\hline \multicolumn{6}{|l|}{ Have you ordered alcoholic drinks? } \\
\hline Yes & 96 & 0.194 & 0.395 & 0 & 1 \\
\hline No & 400 & 0.806 & 0.395 & 0 & 1 \\
\hline \multicolumn{6}{|l|}{ Are you on a diet } \\
\hline Yes & 162 & 0.327 & 0.469 & 0 & 1 \\
\hline No & 334 & 0.673 & 0.469 & 0 & 1 \\
\hline \multicolumn{6}{|l|}{ How often do you eat everything you have ordered? } \\
\hline Never/Rarely & 92 & 0.185 & 0.389 & 0 & 1 \\
\hline Sometimes/Very often & 262 & 0.528 & 0.500 & 0 & 1 \\
\hline Always & 142 & 0.286 & 0.452 & 0 & 1 \\
\hline \multicolumn{6}{|l|}{ I always over order food when dining out } \\
\hline (Strongly) Disagree/Neither agree nor disagree & 336 & 0.677 & 0.468 & 0 & 1 \\
\hline (Strongly) Agree & 160 & 0.323 & 0.468 & 0 & 1 \\
\hline \multicolumn{6}{|l|}{ I will make an effort to reduce food waste } \\
\hline (Strongly) Disagree/Neither agree nor disagree & 100 & 0.202 & 0.402 & 0 & 1 \\
\hline (Strongly) Agree & 396 & 0.798 & 0.402 & 0 & 1 \\
\hline
\end{tabular}

\section{Results and Discussion}

The Tobit model estimates calculated using Stata 16.1 are summarized in Table 3. In addition to these model estimates, we used the Tobit model estimates to derive expected food waste values (along with 95\% confidence intervals) for the overall sample (grand mean). The various subsamples were codified utilizing the covariates' various levels. Within each covariate, pairwise comparisons across the various subpopulations' expected food waste values were conducted and reported in Table 3. Model and expected food waste estimates will be discussed jointly in the remainder of this section. We aimed to identify 
the drivers and determinants of food waste generation while dining out at MediterraneanLebanese restaurants. The respondents' socio-demographic characteristics, such as gender, age, and marital status, did not affect the food waste generation. This was in line with other studies [31-34], which reported that socio-demographic characteristics are modest predictors of food waste generation.

Our results indicated that a Lebanese restaurant diner wasted an average of $179 \mathrm{~g}$ of food. When results are broken down by various restaurant price ranges, diners in both the lower- and higher-range restaurants wasted above the grand mean (208 and $205 \mathrm{~g}$, respectively). While insignificantly different from each other, the food waste level of the former group was significantly different from that of mid-range restaurants, in which an average of $157 \mathrm{~g}$ of food was wasted per person (22 $\mathrm{g}$ less than the grand mean). [35] argued that food price is a significant determinant of food waste avoidance. Whereas diners in higher-price range restaurants tend to have higher incomes, ordering more food and thus paying higher bills is not an issue for them. Additionally, it is observed among such restaurants that the waiters give more suggestions and encourage customers to order more items, compared to lower priced restaurants, for the aim of generating more income, but this also increases food waste at the same time.

On the other hand, in lower price range restaurants, menu items are usually cheaper, and customers tend to over-order food. In contrast, diners at mid-range restaurants usually belong to the middle class, where price is a major determinant in their food choice $[35,36]$. To this category of customers, food waste is perceived as a financial loss [37]. Middle-class customers are price conscious and are reluctant to waste money [38,39]; therefore, they tend to produce less waste $[40,41]$.

When breaking down food waste by the number of persons at the table, results showed that average food waste was highest ( $207 \mathrm{~g}$ per person) among diners at tables with 1-2 people. Food waste significantly dropped to approximately $150 \mathrm{~g}$ per person for tables with three or more people. On the other hand, the number of dishes per person turned out to be a strong food waste driver. Our results show that the average food waste increases significantly from $130 \mathrm{~g}$ per person from tables with up to two dishes served per person, to $205 \mathrm{~g}$ from tables with two to four dishes per person, then again to $281 \mathrm{~g}$ from tables where more than four dishes are served per person. Since Lebanese cuisine involves a large number of mezze platters, ordering more dishes broadens the range of selection for people sitting at the table, which will increase the likelihood of waste generation [42]. Furthermore, since the mezze platters are always shared, the food waste decreases as the number of people at the table increases.

In terms of the company/accompanying party at the restaurant, the results suggest that food waste generated from tables where the respondent is dining alone or with friends or colleagues (169 $\mathrm{g}$ per person) was insignificantly different from the amount of food waste generated from tables where the individual is dining out with one's partner or family member(s) (188 g). Likewise, the main motive for dining out had little significant influence over the amount of food waste generated when contrasting dining for leisure ( $180 \mathrm{~g}$ per person) with dining for business or for convenience (164 g). In terms of accompaniments to food typically ordered in Lebanese restaurants, both narghile and alcohol, when ordered to the table, seemed to contribute significantly to raising food wasted per person. When narghile was ordered to the table, average food waste significantly increased from 152 to $207 \mathrm{~g}$. This can be attributed to the fact that, due to the suppression of appetite from nicotine, smokers tend to eat less and waste more than non-smokers [43]. On the other hand, when alcohol was ordered, food waste increased by a slightly lower amount, namely from 170 to $217 \mathrm{~g}$. Whereas the average number of dishes ordered per person was lower at tables where waterpipe(s)/(hookah) was/were ordered (1.36 dishes vs. 1.70 in tables with no narghile(s)), it was higher in tables where alcohol was ordered (2.12 compared to 1.40 at tables with no alcohol). 
Table 3. Model and expected food waste estimates.

\begin{tabular}{|c|c|c|c|}
\hline Variable & Model & Expected Waste (g/Person) & 95\% Conf. Int. \\
\hline \multicolumn{4}{|l|}{ Model and expected food waste estimates } \\
\hline Constant/Grand mean & $242.79 * * *$ & 178.5 & $(159.4-197.7)$ \\
\hline \multicolumn{4}{|l|}{ Restaurant's price range } \\
\hline LBP50,000 or less for 2 people & - & $207.7^{b}$ & $(166.8-248.6)$ \\
\hline LBP50,001-LBP120,000 for 2 people & $-81.98 * *$ & $157.1^{\mathrm{a}}$ & $(132.9-181.3)$ \\
\hline More than LBP120,000 for 2 people & -3.55 & $205.3^{a b}$ & $(150.6-260.1)$ \\
\hline \multicolumn{4}{|l|}{ Number of people at the table } \\
\hline $1-2$ people & - & 206.8 & $(177.8-235.7)$ \\
\hline 3-4 people & $-86.80^{* *}$ & $153.6^{\mathrm{a}}$ & $(123.5-183.8)$ \\
\hline 6 people or more & $-94.66^{* *}$ & $149.2^{\mathrm{a}}$ & $(105.1-193.3)$ \\
\hline \multicolumn{4}{|l|}{ Number of dishes per person } \\
\hline Up to 2 dishes & - & 130.1 & $(105.6-154.5)$ \\
\hline $2-4$ dishes & $128.55 * * *$ & 205.1 & $(165.3-245.0)$ \\
\hline More than 4 dishes & $234.81 * * *$ & 281.4 & $(228.3-334.5)$ \\
\hline \multicolumn{4}{|l|}{ With whom are you dining out? } \\
\hline Alone/Friends/Colleagues & - & $169.4^{\mathrm{a}}$ & $(143.3-195.4)$ \\
\hline Partner/Family & 30.95 & $188.3^{\mathrm{a}}$ & $(160.6-216.1)$ \\
\hline \multicolumn{4}{|l|}{ Main motive for dining out } \\
\hline Leisure & - & $180.2^{\mathrm{a}}$ & $(160.0-200.4)$ \\
\hline Business/Convenience & -27.16 & $163.9^{\mathrm{a}}$ & $(107.6-220.3)$ \\
\hline \multicolumn{4}{|l|}{ Have you ordered narghile? } \\
\hline Yes & - & 207.0 & $(178.0-236.0)$ \\
\hline No & $-90.02 * * *$ & 152.0 & $(126.7-177.3)$ \\
\hline \multicolumn{4}{|l|}{ Have you ordered alcoholic drinks? } \\
\hline Yes & - & 216.7 & $(167.2-266.3)$ \\
\hline No & $-73.32 *$ & 170.0 & $(148.9-191.0)$ \\
\hline \multicolumn{4}{|l|}{ Are you on a diet } \\
\hline Yes & - & 142.5 & $(112.8-172.2)$ \\
\hline No & $93.32 * * *$ & 197.7 & $(173.5-222.0)$ \\
\hline \multicolumn{4}{|l|}{ How often do you eat everything you have ordered? } \\
\hline Never/Rarely & - & 264.3 & $(212.5-316.0)$ \\
\hline Sometimes/Very often & $-96.24 * *$ & 196.9 & $(169.8-224.1)$ \\
\hline Always & $-260.93^{* * *}$ & 106.9 & $(79.8-134.1)$ \\
\hline \multicolumn{4}{|l|}{ I always over order food when dining out } \\
\hline (Strongly) Disagree/Neither agree nor disagree & - & 165.8 & $(143.3-188.2)$ \\
\hline (Strongly) Agree & $65.99 *$ & 207.0 & $(170.9-243.1)$ \\
\hline \multicolumn{4}{|l|}{ I will make an effort to reduce food waste } \\
\hline (Strongly) Disagree/Neither agree nor disagree & - & 220.7 & $(174.8-266.5)$ \\
\hline (Strongly) Agree & $-81.27 * *$ & 168.7 & $(147.9-189.4)$ \\
\hline \multicolumn{4}{|l|}{ Model fit } \\
\hline Nr. Respondents & 496 & & \\
\hline Log-Likelihood & -2554.14 & & \\
\hline Likelihood ratio $\chi^{2}$ ( $p$-value in brackets) & $119.16(0.000)$ & & \\
\hline Akaike information criterion (AIC) & 5142.27 & & \\
\hline Bayesian information criterion (BIC) & 5213.78 & & \\
\hline
\end{tabular}

Note: (1) Legend: ${ }^{*} p<0.10 ; * * p<0.05 ; * * * p<0.01$. (2) For each covariate, expected waste values sharing the same letter are insignificantly different at the $10 \%$ significance level. For example, with a covariate with three levels, if all three expected waste values share the letter ' $a$ ', then they are all insignificantly different. However, if one has next to it the letter ' $a$ ', the second ' $b$ ', and the third 'ab', then the first two are significantly different, while each is insignificantly different from the third. Finally, if no letters are found next to any of the three values, this means that any two of the three expected waste values are significantly different.

Moving to the behavioral and attitudinal characteristics of survey respondents answering on behalf of the surveyed tables, being on a diet significantly decreased average food waste from 198 to $143 \mathrm{~g}$ per person. People following a diet or watching their weight tend to pay more attention to what they eat, so they usually avoid over-ordering food; in doing so, they limit the quantity of food waste generation. The frequency of eating everything ordered seems to be the strongest determinant of food waste. Here, average food waste at tables whose respondents reported "never" or "rarely" eating everything ordered was 
highest (264 g per person) and significantly more so compared to tables whose respondents reported doing so sometimes or very often $(197 \mathrm{~g})$. In turn, these had an average food waste that was significantly higher than tables whose respondents reported always eating everything ordered $(107 \mathrm{~g})$. As for the tendency to over-order food, respondents who (strongly) agreed they do so had an average food waste level (207 g per person) that was significantly higher than people who did not (166 g). Finally, in terms of attitudes and beliefs, the respondents' pledge to reduce food waste seemed to be significantly consequential, whereby tables with respondents who (strongly) agree to such a pledge had an average food waste figure of $169 \mathrm{~g}$ per person, which was significantly lower than tables whose respondents did not pledge to reduce food waste $(221 \mathrm{~g})$. This was in line with a study in Denmark which reported that attitudes towards and beliefs in the merits of reducing food waste were positively linked to the intention not to waste food [34,44]. Furthermore, when an individual had unfavorable evaluations of food waste behavior, the intention to reduce food waste increased [37,45-47].

Questionnaires were filled by one representative of the table, and one limitation is the fact that some degree of divergence between the behaviors and attitudes of different table customers exist; therefore, responses of one person may not fully reflect the table as a whole. Another limitation is that self-reporting questionnaires are strongly affected by the 'social desirability bias'. In other words, participants are prone to report on what they believe is the socially desirable behavior/attitude, which leads to biased waste estimates [39,48,49].

Food and beverages are deeply embedded in the Lebanese culture. The traditional mezze-based Lebanese cuisine nurtures a love for variety, sharing, and authenticity amongst the Lebanese. The successful restaurateurs in the country rely on these cultural notions to win over the crowd and, most recently, to weather the economic slowdown in business. However, in a country like Lebanon, where the gap between the under-fed and the over-fed is widening rapidly (aggravated by the economic and financial crises, the Beirut blast of August 2020, and the COVID-19 pandemic), thousands of tons of food are wasted daily across the various levels of the supply chain. There is no government body addressing this problem, making it even more challenging. In addition, there is no effective law regarding food waste in Lebanon, nor any authority that checks on restaurants' food waste.

Tackling food waste in restaurants can be accomplished through negative and positive sanctions. Negative sanctions include the imposition of fines and taxes on restaurants that do not make efforts to reduce food waste, including donating their leftover food to charities. Negative sanctions affect the restaurant's image, and hence its clientele. This approach has been in place in Italy and France [50]. However, one also needs to be careful of such sanctions since restaurants may under-report or hide the amount of food waste to avoid sanctions.

On the other hand, positive sanctions involve incentives to motivate restaurants to donate their excess food. Incentivizing restaurants with tax rebates may encourage restaurants to give away their excess food to the needy. Organizations like Lebanese Food Bank, Beit Al Baraka, and Food Blessed have emerged recently in Lebanon, and they have programs to collect excess food from restaurants. One incentive can be issuing tax rebate certificates by these organizations to restaurants in return for food donations. However, the government will have to consider a mechanism to check the transparency of the process. Adopting such approaches across the restaurant sector and increasing awareness among customers can help reduce food waste generation at the restaurant level.

\section{Conclusions}

To address the growing issue of food waste at the restaurant level, an urgent need to effectively reduce plate waste is mandatory. As food waste is not the outcome of a single behavior, our study highlights the drivers and determinants of food waste generation while dining out in Mediterranean-Lebanese restaurants. Our results reported that variables, such as a higher number of people at the table, larger orders of dishes, and ordering 
waterpipe (hookah) and alcohol, contributed significantly to food waste generation. In addition, being on a diet and pledging to reduce food waste significantly decreased food waste generation. In a typical Mediterranean-Lebanese restaurant, the dishes served are numerous and include many appetizers and salads, in addition to fewer main dishes and desserts. While appetizers and salads might be considered plate fillers, rather than part of the meal ordered, some customers do not consider these food types to be actual food.

Combatting food waste in restaurants requires the introduction of fiscal measures by imposing fines and taxes on customers and restaurants that do not make efforts to reduce their food waste. Additional studies must be conducted in the future in other regions of Lebanon. Furthermore, more studies must be carried out to characterize the food waste generated in restaurants.

Author Contributions: Conceptualization, M.G.A.; Formal analysis, A.C. and M.G.A.; Investigation, P.A.; Methodology, A.C. and M.G.A.; Project administration, M.G.A.; Supervision, M.G.A.; Writingoriginal draft, M.G.A.; Writing-review \& editing, A.C., H.F.H. and M.G.A. All authors have read and agreed to the published version of the manuscript.

Funding: This study was funded by the University Research Board (URB) at the American University of Beirut Award number: 103795.

Institutional Review Board Statement: This study was approved by the Institutional Review Board at the American University of Beirut on 20 December 2017.

Informed Consent Statement: Written informed consent has been obtained from the subjects who participated in this study. All participants remain anonymous.

Data Availability Statement: Data may be shared upon request due to University IRB restrictions. Access to the data will require an NDA signature. for more information or data request please contact the corresponding author.

Conflicts of Interest: The authors declare no conflict of interest.

\section{References}

1. Baig, M.B.; Al-Zahrani, K.H.; Schneider, F.; Straquadine, G.S.; Mourad, M. Food waste posing a serious threat to sustainability in the Kingdom of Saudi Arabia-A systematic review. Saudi J. Biol. Sci. 2018. [CrossRef] [PubMed]

2. Baulcombe, D.; Crute, I.; Davies, B.; Dunwell, J.; Gale, M.; Jones, J.; Toulmin, C. Reaping the Benefits: Science and the Sustainable Intensification of Global Agriculture. The Royal Society. Available online: http://centaur.reading.ac.uk/26470/ (accessed on 5 May 2021).

3. UN. The World Population Situation in 2014; UN: New York, NY, USA, 2014.

4. Alamar, M.D.C.; Falagan, N.; Aktas, E.; Terry, L.A. Minimising food waste: A call for multidisciplinary research. J. Sci Food Agric. 2018, 98, 8-11. [CrossRef]

5. Dalilawati, Z.; Azwar, H.K. Factors Influencing Household Food Waste Behaviour in Malaysia. Int. J. Res. Bus. Econ. Manag. 2019, 3, 56-71.

6. Godfray, H.C.; Beddington, J.R.; Crute, I.R.; Haddad, L.; Lawrence, D.; Muir, J.F.; Toulmin, C. Food security: The challenge of feeding 9 billion people. Science 2010, 327, 812-818. [CrossRef] [PubMed]

7. Sakaguchi, L.; Pak, N.; Potts, M.D. Tackling the issue of food waste in restaurants: Options for measurement method, reduction and behavioral change. J. Clean. Prod. 2018, 180, 430-436. [CrossRef]

8. Scherhaufer, S.; Moates, G.; Hartikainen, H.; Waldron, K.; Obersteiner, G. Environmental impacts of food waste in Europe. Waste Manag. 2018, 77, 98-113. [CrossRef] [PubMed]

9. FAO. Global Food Losses and Food Waste; FAO: Rome, Italy, 2011.

10. FAO. Food wastage footprint: Impacts on natural resources; FAO: Rome, Italy, 2013.

11. Principato, L.; Pratesi, C.A.; Secondi, L. Towards Zero waste: An Exploratory Study on Restaurant managers. Int. J. Hosp. Manag. 2018, 74, 130-137. [CrossRef]

12. Giorgi, S. Understanding out of Home Consumer Food Waste; WRAP, Brook Lyndhurst: London, UK, 2013.

13. Ozcicek-Dolekoglu, C.; Var, I. Analysis of food waste in university dining halls: A case study from turkey. Fresenius Env. Bull. 2019, 28, 156-166.

14. Hamerman, E.J.; Rudell, F.; Martins, C.M. Factors that predict taking restaurant leftovers: Strategies for reducing food waste. J. Consum. Behav. 2018, 17, 94-104. [CrossRef]

15. Ofei, K.; Mikkelsen, B.E. Food Waste Food Service. FoodServInSPRIe Project. Meal Sci. Public Health Nutr. 2011. Available online: https://vbn.aau.dk/ws/portalfiles/portal/60351514/FoodwasteNK4no.pdf (accessed on 5 May 2021). 
16. FoodPrint The Problem of Food Waste. 2020. Available online: https://foodprint.org/issues/the-problem-of-food-waste/?cid= 2244\#easy-footnote-bottom-37-1309 (accessed on 5 May 2021).

17. WRAP. Understanding out of Home Consumer Food Waste. 2013. Available online: http://www.wrap.org.uk/sites/files/wrap/ OOH\%20Report.pdf. (accessed on 19 May 2021).

18. Heikkilä, L.; Reinikainen, A.; Katajajuuri, J.-M.; Silvennoinen, K.; Hartikainen, H. Elements affecting food waste in the food service sector. Waste Manag. 2016, 56, 446-453. [CrossRef]

19. Abiad, M.G.; Meho, L.I. Food loss and food waste research in the Arab world: A systematic review. Food Secur. 2018, 10, 311-322. [CrossRef]

20. Drabik, D.; DeGorter, H.; Reynolds, C. A Conceptual and Empirical Framework to Analyze the Economics of Consumer Food Waste. Resour. Conserv. Recycl. 2019. [CrossRef]

21. Walker, H. The Meal: Proceedings of the Oxford Symposium on Food and Cookery; Oxford Symposium: Oxford, UK, 2002; p. 268, ISBN 978-1-903018-24-8.

22. Cavendish, M. World and Its Peoples; Marshall Cavendish: Singapore, 2006; p. 979. ISBN 978-0-7614-7571-2.

23. Green Med Initiative. Waste in Lebanon. Available online: https:/ / gmiproject.eu/?page_id=928\#. (accessed on 19 May 2021).

24. Wang, L.E.; Liu, G.; Liu, X.; Liu, Y.; Gao, J.; Zhou, B.; Cheng, S. The weight of unfinished plate: A survey based characterization of restaurant food waste in Chinese cities. Waste Manag. 2017, 66, 3-12. [CrossRef]

25. Mattar, L.; Abiad, M.G.; Chalak, A.; Diab, D.; Hassan, H. Attitudes and behaviors shaping household food waste generation: Lessons from Lebanon. J. Clean. Prod. 2018, 198, 1219-1223. [CrossRef]

26. Chalak, A.; Abiad, M.G.; Diab, M.; Nasreddine, L. The Determinants of Household Food Waste Generation and its Associated Caloric and Nutrient Losses: The Case of Lebanon. PLoS ONE 2019, 14, e0225789. [CrossRef]

27. Chalak, A.; Abou-Daher, C.; Abiad, M. Generation of food waste in the hospitality and food retail and wholesale sectors: Lessons from developed economies. Food Secur. 2018, 10, 1279-1290. [CrossRef]

28. Zomato. Available online: https:/ / www.zomato.com/beirut (accessed on 19 May 2021).

29. Baum, C.F. An Introduction to Modern Econometrics Using Stata; College Station Stata Press: College Station, TX, USA, 2006.

30. Wooldridge, J.M. Introductory Econometrics: A Modern Approach, 5th ed.; South-Western Cengage Learning: Mason, OH, USA, 2012

31. Falasconi, L.; Cicatiello, C.; Franco, S.; Segrè, A.; Setti, M.; Vittuari, M. Such a shame! A study on self-perception of household food waste. Sustainability 2019, 11, 270. [CrossRef]

32. Grasso, A.C.; Olthof, M.R.; Boevé, A.J.; van Dooren, C.; Lähteenmäki, L.; Brouwer, I.A. Socio-Demographic Predictors of Food Waste Behavior in Denmark and Spain. Sustainability 2019, 11, 3244. [CrossRef]

33. Koivupuro, H.K.; Hartikainen, H.; Silvennoinen, K.; Katajajuuri, J.M.; Heikintalo, N.; Reinikainen, A.; Jalkanen, L. Influence of socio-demographical, behavioural and attitudinal factors on the amount of avoidable food waste generated in Finnish households. Int. J. Consum. Stud. 2012, 36, 183-191. [CrossRef]

34. Stancu, V.; Haugaard, P.; Lähteenmäki, L. Determinants of consumer food waste behaviour: Two routes to food waste. Appetite 2016, 96, 7-17. [CrossRef] [PubMed]

35. Abdelradi, F. Food waste behaviour at the household level: A conceptual framework. Waste Manag. 2018, 71, 485-493. [CrossRef] [PubMed]

36. Filimonau, V.; Gherbin, A. An exploratory study of food waste management practices in the UK grocery retail sector. J. Clean. Prod. 2017, 167, 1184-1194. [CrossRef]

37. Graham-Rowe, E.; Jessop, D.C.; Sparks, P. Identifying motivations and barriers to minimising household food waste. Res. Conserv. Recycl. 2014, 84, 15-23. [CrossRef]

38. Pellegrini, G.; Sillani, S.; Gregori, M.; Spada, A. Household food waste reduction: Italian consumers' analysis for improving food management. Br. Food J. 2019, 121, 1382-1397. [CrossRef]

39. Williams, H.; Wikström, F.; Otterbring, T.; Löfgren, M.; Gustafsson, A. Reasons for household food waste with special attention to packaging. J. Clean. Prod. 2012, 24, 141-148. [CrossRef]

40. Aschemann-Witzel, J.; Zielke, S. Can't Buy Me Green? A Review of Consumer Perceptions of and Behavior Toward the Price of Organic Food. J. Consum. Aff. 2017, 51, 211-251. [CrossRef]

41. Aktas, E.; Sahin, H.; Topaloglu, Z.; Oledinma, A.; Huda, A.K.S.; Irani, Z.; Sharif, A.M.; van't Wout, T.; Kamrava, M. A consumer behavioural approach to food waste. J. Enterp. Inf. Manag. 2018, 31, 658-673. [CrossRef]

42. Gunders, D. Wasted: How America is Losing Up to 40 Percent of Its Food from Farm to Fork to Landfill. Nat. Resour. Def. Counc. 2017. Available online: https:/ / www.nrdc.org/sites/default/files/wasted-2017-report.pdf (accessed on 19 May 2021).

43. Perkins, K.A.; Sexton, J.E.; DiMarco, A.; Fonte, C. Acute effects of tobacco smoking on hunger and eating in male and female smokers. Appetite 1994, 22, 149-158. [CrossRef]

44. Bolton, L.; Alba, J. When less is more: Consumer aversion to unused utility. J. Consum. Psychol. 2012, 22, 369-383. [CrossRef]

45. Barone, A.M.; Grappi, S.; Romani, S. The road to food waste is paved with good intentions: When consumers' goals inhibit the minimization of household food waste. Resour. Conserv. Recycl. 2019, 149, 97-105. [CrossRef]

46. Stefan, V.; van Herpen, E.; Tudoran, A.A.; Lähteenmäki, L. Avoiding food waste by Romanian consumers: The importance of planning and shopping routines. Food Qual. Prefer. 2013, 281, 375-381. [CrossRef] 
47. Visschers, V.; Wickli, N.; Siegrist, M. Sorting out food waste behaviour: A survey on the motivators and barriers of self-reported amounts of food waste in households. J. Environ. Psychol. 2016, 45, 66-78. [CrossRef]

48. Schanes, K.; Dobernig, K.; Gözet, B. Food waste matters-A systematic review of household food waste practices and their policy implications. J. Clean. Prod. 2018, 182, 978-991. [CrossRef]

49. Van Herpen, E.; van der Lans, I.A.; Holthuysen, N.; Nijenhuis-de Vries, M.; Quested, T.E. Comparing wasted apples and oranges: An assessment of methods to measure household food waste. Waste Manag. 2019, 88, 71-84. [CrossRef]

50. Aamir, M.; Ahmad, H.; Javaid, Q.; Hasan, S. Waste not, want not: A case study on food waste in restaurants of Lahore, Pakistan. J. Food Prod. Mark. 2018, 24, 591-610. [CrossRef] 